\title{
Ethnic Issues in China's Northwest Frontier Regions and Its Solutions \\ DOI: https://doi.org/10.47175/rissj.v1i3.97
}

| Yang Liao' | Li Meng ${ }^{2 *}$
${ }^{1}$ School of Public
Management, South China
Agricultural University,
China
${ }^{2}$ News Centre of South
China Agricultural
University, China
${ }^{*}$ ly2008@scau.edu.cn

\begin{abstract}
The Northwestern Frontier of China is different from the Northwestern China in that it is only a part of the Northwestern China that is close to the border of the country. The geographic space of the northwestern frontier in different periods of Chinese history has changed with the effective governance of the Chinese central government. The ethnic issues in the northwestern frontier have their basic historical background and time and space. The types of ethnic issues in China's northwest frontier areas are not the same, but they are basically manifested in internal socioeconomic and cultural development issues and external ethnic interaction issues, as well as transnational (border) ethnic issues and ethnic religious issues, such as ethnic separatism and extreme religion. Doctrine and violent terrorism are only part of it, not all of it. To this end, it is necessary to "prescribe the right medicine" for different types of ethnic problems and formulate different effective "prescriptions" to solve ethnic problems in order to realize the "Chinese dream" of harmonious socialist ethnic relations in China.
\end{abstract}

KEYWORDS

Northwest China; Northwest Frontier; Ethnic Issues; EthnicReligious Issues; Ethnic Development; Public Governance

\section{INTRODUCTION}

From a conceptual point of view, Northwest China is only a geographic space or geographic unit. However, the convergence and radiation of diverse ethnic and religious cultures in history has created a unique social and historical scene in Northwest China.

The Northwestern Frontier of China is different from the Northwestern China in that it is only a part of the Northwestern China that is close to the border of the country. What ethnic problems exist in this part of the region? How is it similar to the ethnic issues in Northwest China? This is a problem that is easily overlooked in previous studies.

In fact, the explanatory framework of the center-periphery theory needs to be revised. For China's northwestern frontier, where is its economic and cultural "center" apart from the political and military center (the center)? Where are the secondary centers and secondary edges?

The types of ethnic problems between Inner Mongolia, which straddles the "Three Norths" (Northeast, North China, and Northwest), and Ningxia, Gansu, Xinjiang, and Tibet running through the southwest and northwest are not the same, but they are basically manifested as internal socioeconomic and cultural development issues With regard to external ethnic relations, as well as transnational (border) ethnic problems and ethnic religious problems, ethnic separatism, extreme religiousism, and violent terrorism are only part of it, not all of it. 
To this end, it is necessary to "prescribe the right medicine" for different types of ethnic problems and formulate different effective "prescriptions" to solve ethnic problems in order to realize the "Chinese dream" of harmonious socialist ethnic relations in China.

\section{RESEARCH METHODS}

With regard to the study of ethnic issues in northwestern China, Chinese domestic masters and doctoral dissertations pay more attention. Yan Wenhu (2006) analyzed the impact of the contemporary Islamic Revival Movement on China's national security from the perspectives of geopolitics, economy, military, and military struggle against Taiwan. Zhang Yuling (2006) took the ethnic relations in Urumqi and Yinchuan as examples to compare and analyze the ethnic relations in cities in the Northwestern National Autonomous Region. Guo Shengli (2010) believes that the formulation and implementation of the Northwest Ethnic Policy of the Republic of China Government had a significant impact on the situation in the Northwest during the Republic of China. Wang Shuliang (2010) analyzed the impact of the US Central Asia policy on the security of China's northwestern region from the perspective of geopolitics. Li Shiyong (2014) analyzed the contemporary Qinghai Haixi Mongolian, Tibetan and Han ethnic relations.

Tan Zhenghao (1998) analyzed the ways and means of religion's influence on political stability in the ethnic regions of Northwest China. Chen Lianbi (2001) discussed the complex ethnic structure, ethnic contradictions and their impact on cross-border ethnic issues in Northwest China after the independence of Central Asian countries. Wang Xin and Zhou Weizhou (2001) combined historical experience and lessons with the socioeconomic status of the Northwest ethnic groups, and put forward new ideas for handling Northwest ethnic issues under the conditions of a socialist market economy.

Wang Chunyan (2006) analyzed the role of urbanization in promoting the common prosperity and development of all ethnic groups in Northwest China, and believed that cities are the core of driving the economic and social development of a region. Urbanization is the only way for all ethnic groups in Northwest China to gradually realize modernization. Chen Huayu and Rong Ning (2008) believe that ethnic groups with a small population in the Islamic cultural circle in the northwest must start from the backward living environment of the local area, change their economic growth mode, and actively develop characteristic economies in order to better solve ethnic problems. Zhao Hujing, Yuan Haiying, and Jia Zhike (2009) advocated that during the implementation of China's western development strategy, we must resolutely combat ethnic separatist activities and terrorism, strengthen the legal system, strive to develop the national economy, promote national unity, and form a joint force for the development of all ethnic groups and the entire society.

Yang Deliang and Ma Xiaoqin (2009) used Shiwan Village in Ningxia as a case to investigate the status quo and problems of social security in rural areas in ethnic minority areas in Northwest China. Hu Zhaoyi (2012) used Dongxiang Autonomous County in Gansu Province as an example to analyze rural poverty in ethnic minority areas in Northwest China.

In addition, Meng Xiaoyan (2005), Shang Mingrui (2011), An Jian (2011), Zhang Yuqing (2011), Zhu Xiaoming (2013), Ma Zhongcai (2015), Qiu Liying (2018) and others are also discussed on ethnic issues in Northwest China.

Maslak, Mary Ann (2010) used Northwest China as a case to discuss the issue of participation in education in China. Wan Minggang (2017) analyzed the cultural conflict and integration issues of ethnic education in Northwest China. Chen Liu, Rong Yang, Desheng Xue (2018) elucidates how Chinese Northwest Muslims use food to sustain their 
religious identities, how they manage their food practices when eating with Han Chinese and how such daily food practices integrate them into or exclude them from the mainstream Han Chinese culture in relation to wider socio-political issues.

On the whole, scholars in the disciplines of ethnology, political science, and pedagogy in China have conducted more and in-depth studies on ethnic issues in Northwest China. Foreign scholars have seldom studied ethnic issues in Northwest China, especially researchers in the English-speaking world have less exchanges with Chinese domestic scholars.

This article mainly uses literature analysis and comparative research methods to analyze the temporal and spatial background, types and solutions of ethnic problems in Northwest China.

\section{RESULTS AND DISCUSSION}

\section{The Temporal and Spatial Field Of Ethnic Issues in China's Northwestern Frontier}

To accurately grasp the ethnic issues in the northwestern frontier area today, we need not only to care about the concept of ethnic issues, but also to analyze their different time and space fields in order to gain a deeper understanding. Today, scholars still have different understandings of the concept of ethnic issues. Yang Liao (2010) has also paid more attention to this in recent years, trying to analyze the relationship between ethnic issues, religious issues and ethnic religious issues, and finally published in the magazine 'World Ethnics' under the title 'National-Religious Issues: Concept, Type and Essence'. In this thesis, Yang Liao (2010) defines 'national issues' as: 'national issues include not only the development of the nation itself (including the process of ethnic morphology), but also between nations, nations and classes, nations, and nations and other nations. The issue of relations between nations. In other words, national issues are the sum of national conflicts and conflicts arising from national interests and rights during the development of national societies.' This definition broadly clarifies the essential connotations of national issues and their Basic extension.

The frontier is a product of the political concept of a modern sovereign state, which is relative to the central ruling center of a unified country. During the Shang and Zhou dynasties, the boundary between the "central dynasty" and the enfeoffment of small states and fiefs was relatively general and vague. The so-called 'Hou', 'Dian', 'Sui', 'Yao', and 'Huang' five categories of surrender, although they reflect the hierarchical distance in geographical space, they are based on the tribute of different items, rather than the true modern meaning. It is a sovereign frontier that unites the political, military, economic, and cultural aspects of the country.

The periphery of Wangji in ancient times was divided into five hundred li, from near to far, it was divided into Houfu, Dianfu, Suifu, Yaofu, and Huangfu, collectively called 'Wu $F u$ '. 'Shu.Yiji': 'Mixed into $W u F u$, as for five thousand.' Kong Yingda's comment: 'Wu $F u, H o u$, Dian, Sui, Yao, and Huangfu. Fu, are five hundred $l i$. The four directions are five thousand $l i$ apart.' Also, 'Book $\bullet$ Kanggao' said that $W u F u$ were called Hou, Dian, Nan, Cai and Wei in Zhou Dynasty.

The theory of ' $W u F u$ ' was first seen in 'Shangshu•Yugong'.It says: 'Five hundred li formed the Domain of the Sovereign. From the first hundred they brought as revenue the whole plant of the grain; from the second, the ears, with a portion of the stalk; from the third, the straw, but the people had to perform various services; from the fourth, the grain in the husk; and from the fifth, the grain cleaned. Five hundred li (beyond) constituted the Domain of the Nobles. The first hundred li was occupied by the cities and lands of the 
(sovereign's) high ministers and great officers; the second, by the principalities of the barons; and the (other) three hundred, by the various other princes. Five hundred li (still beyond) formed the Peace-securing Domain. In the first three hundred, they cultivated the lessons of learning and moral duties; in the other two, they showed the energies of war and defense. Five hundred li (remoter still) formed the Domain of Restraint. The (first) three hundred were occupied by the tribes of the $\hat{\mathrm{I}}$; the (other) two hundred, by criminals undergoing the lesser banishment. Five hundred li (the most remote) constituted the Wild Domain. The (first) three hundred were occupied by the tribes of the Man; the (other) two hundred, by criminals undergoing the greater banishment.'Guo Yu•Zhou Yu(Shang)' contains: 'The system of the ancestors was: Wangji was called Dian Fu, Wangji was called $\mathrm{Hou} \mathrm{Fu}$, outside of $\mathrm{Hou} \mathrm{Fu}$ was called Bin $\mathrm{Fu}$, the place where barbarians lived was called $Y a o F u$, and the place where Rong di lived was Huang Fu.' The barbarians in the southeast were more responsible for serving the emperor Zhou than Rong Di in the northwest, which to a certain extent reflected that the Zhou royal family's governance of Rong di society in the northwestern frontier was relatively loose. Wang Hui (2013) believes that the reason for the difference between the "required service" and "wild service" of the barbarians in the southeast and Rong $D i$ in the northwest is the difficulty of controlling the products and the agricultural/nomadic society. This makes some sense. In other words, the instability of the nomadic society is one of the important factors that caused the ethnic social problems in the northwestern frontier.

Since the Qin and Han dynasties, after the establishment of the political system of the central feudal dynasty, the relationship between the central and local governments and between the central and the frontiers was gradually established, and the frontiers or 'governances' were managed by means of war, intermarriage, mutual market, trade, tribute, canonization, farming, and border defense. It formed management systems such as the Jimi Prefecture Mansion and the Tusi native officials. In the Ming and Qing Dynasties, relatively complete border governance policies and border management systems were formed.

After the Opium War, the Western powers set off a frenzy to carve up China, and China's northwestern frontier was gradually reduced to the sphere of influence of Russia and Britain. If we say that the ethnic problems in the northwestern frontier region of China before modern times are mainly due to the interactions between the ancient nomads and the nomads, the nomads and the agricultural peoples (Han nationality) caused by the north and northwest nomadic people's own ethnic form and the needs of economic and social development. In terms of contradictions or conflicts, then the ethnic issues in the northwestern frontier of China after modern times have incorporated more transnational ethnic factors, and the invasion and interference of foreign powers has made China's domestic border ethnic issues mixed with international factors.

During the period of the Republic of China, the concept of a Western sovereign state became popular among Chinese bourgeois revolutionaries, and the idea of the 'five ethnic groups' of Han, Manchu, Mongolian, Hui, and Tibet was once cherished. However, in the era of warlord separatism, melee and war of resistance against Japanese aggression, and wars of liberation, the 'five ethnic republic' was only a vision, but it was difficult to realize it. Between nations, nations and classes, nations and nations, even between countries, there are ethnic conflicts or ethnic conflicts arising from ethnic interests and ethnic rights. These ethnic contradictions or conflicts include not only the contradictions between the various Chinese nationalities and the Manchu rulers at the domestic level, but also the struggle between the Chinese nation and the nation-state against the Japanese militarist invaders. 
It goes without saying that in this situation of internal and external troubles and internal and external wars, the ethnic issues in the northwestern frontier region are diverse and complex: the long-term domestic warlord melee and the Kuomintang-Communist war have deprived the frontier ethnic regions of economic, social and cultural development. Stable environment, but it also provided experience and lessons for building socialist ethnic relations after the founding of New China; Japan's war of aggression against China put all the Chinese peoples in danger of national subjugation, while the brave resistance and defeat of the Japanese invaders by all the Chinese peoples The construction of socialist national relations after the founding of New China has provided historical reference.

It can be said that the construction practice of equality, unity, mutual assistance, and harmony in China's socialist ethnic relations is not only a summary of the historical experience of ethnic issues and their solutions before the founding of New China, but also a summary of the Marxist ethnic theory after the founding of New China. The system innovation combined with the specific practice of solving Chinese ethnic problems has explored a new path for the ultimate solution of Chinese ethnic problems. The 'Northwestern Frontier Region' in the Xia, Shang and Zhou Dynasties was obviously much smaller than China's northwestern frontier region after the Qin Dynasty was unified to the Qing Dynasty's basic layout, and the geographic boundaries were relatively blurred. The more the history develops, the stronger the boundary awareness. From the uncivilized areas to the minorities becoming the subjects of the Central Plains dynasty, the continuous civilization, the expansion of the territory, and the 'strategic' of frontier governance are therefore valued by the central rulers of China. Although the Sino-Russian treaty demarcation also existed in the middle and early Qing Dynasty, the northwestern frontier of China was basically stable.

Since modern times, the invasion of foreign powers has highlighted the border crisis, and the ethnic issues in China's northwest border areas have changed from the inside out. During the period of the Republic of China, ethnic issues in the northwestern frontier of China were more complicated, and the interests or rights of survival, development, and protection of ethnic culture were all affected to varying degrees. This is the basic situation in the historical process of China's northwest frontier, and it is also the basic space-time field of ethnic issues in China's northwest frontier.

\section{Types, Contents and Expressions of Ethnic Issues in the Northwestern Frontier Region}

The northwest frontier region of China today is the historical continuation of the ancient northwest frontier region, but its ethnic issues are different from those of the region before the founding of the People's Republic of China. The ethnic issues in the history of the region may have some historical connections with contemporary ethnic problems, but it cannot be regarded as a contemporary ethnic problem. Otherwise, it will be easy to make mistakes. The "present" mentioned in this article refers to the more than 70 years since the founding of the People's Republic of China.

\section{Border Trade and Social Stability}

The border trade in the northwestern frontier of China is related to the local social stability, but border trade is not the only factor that affects the local social stability, but only its incentive. However, local social stability or otherwise will adversely affect border trade.

The first-class and second-class ports in the northwestern frontier region of China (including the western part of the Inner Mongolia Autonomous Region) have many border trade ports connecting Mongolia, Russia, and some countries in Central Asia. However, 
due to the socio-economic conditions and natural resources of the border areas of the northwestern provinces, Infrastructure, border trade policies, especially tax and fee concessions, and the differences in the importance and policy practices of the central and local governments of the countries where the ports are connected have made the development of border trade between different provinces in the northwestern region greater gap.

Comparing border trade between neighboring provinces in China's northwest frontier is prone to imbalance and even ambivalence. For example, as the only border county between Gansu Province and Mongolia, the relevant leaders and people of Subei Mongolian Autonomous County and its higher-level government Jiuquan City, as well as the border residents of Mazongshan Town, Subei Mongolian Autonomous County, have given great hope for border trade. And often compare the border trade of Mazongshan with the development status of Ceke Port in Inner Mongolia and Laoyemiao Port in Barkol Kazakh Autonomous County of Hami Region, Xinjiang. I am impressed by the prosperity of the border trade ports in Inner Mongolia and Xinjiang, but I am helpless at Mazongshan Port difficulty in resumption. Although Jiuquan City of Gansu Province and the Mongolian Ge and $\mathrm{Ba}$ provinces have conducted many consultations on the establishment, customs clearance, and customs resumption, the issue of customs resumption at this port is still difficult to properly resolve.

According to the document "Suzhengbanfa [2015] No. 81" issued by the People's Government Office of Subei Mongolian Autonomous County on March 15, 2015, the MaZongshan Port of the county has yet to be rehabilitated, and the county's Development and Reform Bureau and Commerce Bureau The bureau, in coordination with relevant departments, sought support from Gansu Province and Jiuquan City to complete the customs resumption work at Mazongshan Port by the end of December 2015(People's Government Office of Subei Mongolian Autonomous County, Gansu Province,2015). 'At present, the Talin copper-gold mine, 70 kilometers away from the Mazongshan port, has predicted gold reserves of 99 tons. The Swiss have done preliminary geological work, but our focus is still on building transportation roads. Many experts believe 'This is the practice of turning the cart before the horse', and suggested that 'in Mongolia's Gobi Altai, Bayanhongguoer, and South Gobi provinces, the three provinces of Altai, Bayanhongoer, and South Gobi should cooperate in risk prospecting within 500 kilometers of the border, and identify mines with large reserves and high grades. Obtain the right to use in an uninterrupted manner, and then proceed with development; select areas with intensive mineral resources to jointly establish economic development zones with the Mongolian local government, concentrate development, actively cooperate with Mongolia's application for preferential policies, and establish mining enterprises and primary processing in the form of sole proprietorship or joint venture Enterprises; domestic select advantageous areas to establish resource deep processing zones to complement foreign enterprises to obtain downstream products and processing income; strive to make foreign resources into brands, and use this to absorb the gathering and investment of all parties to form new development highlights and economic growth point.'(He Chengjun,2006)

It should be said that the demands and hard practices of the officials and people of border counties in Gansu Province to develop border trade are understandable and reasonable. But the problem is that the development of border trade involves not only the mutual support and cooperation between ports and ports, but also the mutual trust and joint actions between countries, regions and regions, and between nations.

As an ethnic region, the economic volume of border trade at Mazongshan Port in Subei Mongol Autonomous County cannot be compared with Xinjiang and Inner Mongolia, 
which are important border provinces. It is more of an ethnic region with the characteristics of border trade. significance. However, the survival and development of border residents in Mazongshan Town of Subei Mongolian Autonomous County is a matter of concern. The local border residents and the people at the border ports of Inner Mongolia and Mongolia belong to the Mongolian ethnic group. From the perspective of the economic dimension of the ethnic process, undoubtedly need to develop simultaneously.

In this sense, the restoration of border trade at the Mazongshan Port in Subei Mongolian Autonomous County and the promotion of its economic, social, and cultural coordinated development are not only related to local social stability, but also to the development of its own ethnic group.

\section{Contradiction between Autonomous and Non-Autonomous Ethnic Groups in}

\section{Border Areas}

The system of ethnic regional autonomy is an institutional arrangement used by the Communist Party of China and the Central People's Government of China to resolve ethnic issues in China after the founding of the People's Republic of China. In China's ethnic regional autonomous areas, due to historical factors, there are often autonomous and non-autonomous ethnic groups. In the course of their political, economic, social, and cultural development in autonomous areas, there are certain differences in economic conditions, national culture, and ideology. A little carelessness can easily cause friction or contradictions in the process of national exchanges.

Xinjiang is located in the hinterland of the Eurasian continent, with a land border of more than 5,600 kilometers. The surrounding area is bordered by eight countries including Mongolia, Russia, Kazakhstan, Kyrgyzstan, Tajikistan, Pakistan, India, and Afghanistan. There are Han, Uygur, and Kazakhs, Hui, Kirgiz, Mongolian, Tajik, Xibe, Manchu, Uzbek, Russian, Daur, and Tatar 13 inhabitants. As of the end of 2012, Xinjiang has a total population of $22,327,800$, a Han population of $8,746,148$, accounting for $40.1 \%$ of the total population, and a minority population of $13,06,186$, accounting for $59.9 \%$ of the total population. The region has 5 autonomous prefectures, 7 regions, and 2 Prefecture-level cities; 88 counties (cities), including 32 border counties (cities), 6 ethnic autonomous counties, and 5 county-level municipalities; 857 townships, including 42 ethnic townships. The Xinjiang Production and Construction Corps is an important part of the autonomous region, with 14 divisions, 175 farms and pastoral groups under its jurisdiction, and a total population of about 2.57 million.

Xinjiang has a vast territory and many ethnic groups, but the development of various regions is uneven. Generally speaking, the economic development of northern Xinjiang is better than that of southern Xinjiang, and there are also certain differences between eastern and western Xinjiang. The reasons are not only resource endowments, but also factors such as transportation, infrastructure and capital, technology, and markets. However, some ethnic minority people did not realize the real reason for their relative backwardness, but listened to people's delusion and attributed it to the "occupation" of resources by the Han nationality or other non-autonomous ethnic groups. In some areas of Xinjiang, there have been some radical remarks about the influence of "killing the Han and returning to Kazakhs" and undermining ethnic unity. This casts a heavy shadow on the ethnic unity and development and prosperity of the region, and also buried the ethnic problems in Xinjiang. The root of thought that detonated at any time. 


\section{Border Ethnic Identity and National Identity Changes}

From the late 1950s to the early 1960s, China went through a difficult period of three years. The relationship between Canada and the Soviet Union deteriorated. The ethnic identity and national identity of some ethnic minorities in China's northwestern frontier region deviated. The KGB instigated the former Soviet Union In 1962, more than 60,000 border residents in Altai, Tacheng, Bortala, and Yili areas in Xinjiang defected to the former Soviet Union (Song Fengying,1962; Zhang Shude,1962). Although this is related to the agitation and instigation of the former Soviet Union, it has a lot to do with the dislocation of the ethnic identity and national identity of the ethnic minorities in Xinjiang border areas. It is said that these "defection" border residents in Xinjiang wanted to return to China after the collapse of the Soviet Union, but they were already naturalized and could not return freely.

\section{The 'Three Forces' Abroad Affect the Unity and Stability of Domestic Ethnic Groups}

Since most of Xinjiang and Central Asia have experienced Turkicization and Islamization in history, some foreign hostile elements tried to separate Xinjiang from China and establish the so-called "East Turkistan" state; there are also some foreign Islamic fundamentalists Through overseas training of backbone elements of ethnic separatism, violent terrorism, religious extremism, and religious infiltration in Xinjiang, the unity of ethnic groups is undermined. The '7.5 Incident' in Xinjiang in 2009 is a typical case. In addition, there are the ' 4.23 ' violent terrorist incident in Xinjiang Bachu in 2014, the '4.30' Urumqi South Railway Station violent terror case, and the '5.22' Urumqi case. The violent terror case in the vegetable market, the ' $6 \cdot 15$ ' terror case in Hotan, Xinjiang, the ' 6.21 ' violent terror case in Yecheng County, Xinjiang's attack on public security agencies, the '7.28' violent terror incident in Shache County, Xinjiang, '9.11' the violent terrorist attack on Luntai in Xinjiang, etc.

In recent years, the penetration and influence of the 'Three Forces' overseas has spread from Xinjiang to the Southwest and South China. The 2014 '3.1' violent terrorist incident at Kunming Railway Station, the '5.6' Guangzhou Railway Station violent terrorist incident, and the 2015 ' $3 \cdot 6$ ' Guangzhou Railway Station violent terrorist incident also brought national unity and social stability negative impact.

\section{CONCLUSION}

To sum up, there are different types of ethnic problems in the border areas of northwest China today. Different types of ethnic problems should not be conflated. Instead, we should 'prescribe the right medicine' for different types of ethnic problems 'prescription':

Border trade and social stability ethnic issues should be coordinated from the perspective of the harmonious and stable development of border ethnic communities in border areas, and coordinate border trade between countries, provinces, regions, cities, counties (banners), and townships. In the 'game' of enriching the people, we coordinate the border trade of different administrative divisions. While 'rich borders' and 'fix borders', we pay attention to the development of ethnic communities in border areas and promote border residents through the economic, political, and cultural processes of border ethnic groups. The overall sublimation of the national process.

Regarding the ethnic issues of autonomous and non-autonomous ethnic groups in border areas, and border ethnic identity and national identity changes, the key is to do a good job in national unity education and propaganda work, so that Marxist nationalism and China's equality, unity, mutual assistance, and harmony The concept of a new type of ethnic 
relations has been deeply rooted in the hearts of border people and transformed into concrete actions and practices in their daily lives.

The 'Three Forces' abroad affect the national unity and stability of the national issues in the country, except for joint and severe crackdowns with neighboring countries, we must further strengthen national unity education and propaganda work, and earnestly achieve 'two hands, both hands are hard'; both must be eliminated The soil for the survival of the 'Three Forces' abroad must also soothe people's hearts, strengthen national unity in the 'bustling foreigners and security', and promote the harmonious development of a unified, stable, prosperous, democratic, civilized, and rule of law society in our multi-ethnic country.

\section{REFERENCES}

An Jian. (2011). On Cross-National Ethnic Issues of Northwest Frontier in China. Journal of Northwest Normal University (Social Sciences), 48 (6):47-50.

Chen Huayu, Rong ning. (2018). Research into the Economic Development of Less Population Nationalities Believed in Islam in Northwest Area. Journal of Qinghai Nationalities Institute, 34(4):79-81.

Chen Lianbi. (2001). Ethnic Relations in the Five Central Asian Countries, Russian, East European \& Central Asian Studies: 42-47.

Chen Liu, Rong Yang, Desheng Xue (2018).Chinese Muslims' daily food practices and their geographies of encounter in urban Guangzhou. Social \& Cultural Geography, DOI:10.1080/14649365.2018.1550583.

Guo Shengli. (2010). Research on the Northwest Ethnic Policy of the Republic of China. Doctoral Dissertation of Lanzhou University. Lanzhou, China

He Chengjun. Ma Zongshan Port: When will the switch be? The Gansu Channel of Xinhuanet was transferred to the Gansu Economic Daily, http://www.gs.xinhuanet. com/news/2006-08/31/content_7918463_5.htm.

$\mathrm{Hu}$ Zhaoyi. (2012). Research on the Rural Poverty in the Ethnic Minority Regions of Northwest China: Taking Dongxiang Autonomous County of Gansu Province as an Example. Journal of Ningxia University (Humanities \& Social Sciences Edition), 34(5):131-135.

Li Shiyong. (2014). Contemporary Qinghai Haixi Mongolian, Tibetan and Han Nationality Relations. Doctoral Dissertation of Lanzhou University. Lanzhou, China.

Ma Zhongcai. (2015). Social Roots of Ethnic Issues: Social Differentiation's Influence on Ethnic Development and Ethnic Relations in Western China. Journal of Beifang University for Nationalities (Philosophy and Social Sciences Edition): 59-62.

Maslak, Mary Ann. (2010). Educational engagement in China: A case from the Northwest. International Journal of Educational Development, Vol.30, Issue3, pp.254-262.

Meng Xiaoyan. (2005). On the Current Problems and Countermeasures in the Development of Ethnic Relations in Northwest Minority Regions. Journal of Sichuan Institute of Socialism: 46-48.

Qiu Liying (2018). Research on the Security of Ideology in Northwest Minority Regions under the Multicultural Background. Master Thesis of Northwest Normal University. Lanzhou, China.

Shang Mingrui. (2011). Poverty Alleviation and Development, Ecological Restoration and Reconstruction and Environmental Protection in Northwest Minority Regions. Social Science Front: 66-76.

Song Fengying. (2005). The Evacuation of Xinjiang Frontier Peoples in 1962. Literary Circles of Cpc History: 4-8. 
Tan Zhenghao. Religion and Political Stability in Northwestern Minority Regions. JOURNAL OF THE NORTHWEST NORMAL UNIVERSITY (SOCIAL SCIENCES), 1998,36(6):3-5.

The People's Government Office of Subei Mongolian Autonomous County, Gansu Province. Notice on Decomposing and Implementing the Main Tasks Determined by the First Plenary (Expanded) Meeting of the Municipal Government in 2015 (Suzheng Banfa [2015] No. 81). http://www.subei.gov.cn/ReadNews.asp?News ID=5672.

Wan Minggang. Cultural Conflict and Integration: China Northwest Ethnic Minority Education. Chinese Education \& Society, 2017, Vol.50, No.1, pp.1-3.

Wang Chunyan. Urbanization: Research Angle of the Common Prosperity of Northwest Various Nationalities. Nationalities Research in Qinghai, 2006,18(2):77-81.

Wang Hui. A New Proof of the Western Zhou Dynasty Barbarians' 'Ask to Serve'. EthnoNational Studies,2003(1):58-69.

Wang Xin \& Zhou Weizhou. On the Northwest Ethnic Issues in the Development of the West. Journal of Northwest University (Philosophy and Social Sciences Edition), 2001,31(4):10-17.

Yan Wenhu, Research on Contemporary Islamic Revival Movement and China's National Security, Doctoral Dissertation of Northwest University. Xi'an, China, 2006.

Yang Deliang \& Ma Xiaoqin. The Status Quo and Problems of Rural Social Security in Northwestern Minority Regions: Taking Shiwan Village in Ningxia as an Investigation Case. Social Sciences in Ningxia,2009(3):61-64.

Yang Liao. National-Religious Issues: Concept, Type and Essence. Journal of World Peoples Studies, 2010(3):8-16.

Zhang Shude. The inside story of 60,000 border residents defecting to the Soviet Union in 1962.People's Digest, 2013(5):72.

Zhang Yuling. Research on the Ethnic Relations in the Cities of the Northwest Ethnic Autonomous Region--Taking the Ethnic Relations in Urumqi and Yinchuan as an Example. Master Thesis of Northwest University for Nationalities. Lanzhou, China,2006.

Zhang Yuqing. The Prominent Problems and Countermeasures in the Process of Modernization in the Northwest Minority Regions. Journal of Chongqing University of Science and Technology (Social Sciences Edition),2011(4):85-86.

Zhao Hujing, Yuan Haiying, Jia Zhike. Analysis of Northwestern Ethnic Issues in the Development of West China. Theory Research,2009(18):38-41.

Zhu Xiaoming. On National Unity and Construction of Harmonious Society in Northwest Minority Regions. Qinghai Social Sciences, 2013(1):143-146. 